\title{
Frontal sinus as an adjuvant in personal and gender identification - A morphometric digital study
}

\author{
Varsha Kanjani ${ }^{1, *}$, Abha Rani ${ }^{2}$, Rajeshwari G. Annigeri ${ }^{3}$, Manjunatha M.R ${ }^{4}$ \\ ${ }^{1,2}$ Student, ${ }^{3} \mathrm{HOD},{ }^{4}$ Associate Professor, Dept. of Oral Medicine \& Radiology, College of Dental Sciences, Davanagere, \\ Karnataka, India
}

*Corresponding Author: Varsha Kanjani

Email: varshakanjani0@gmail.com

\begin{abstract}
Introduction: Human radiography plays a major role for personal and gender identification in case of natural disasters such as earth quacks, tsunamis, etc. when human remains are decayed or deceased. The uniqueness in dimensions and patterns of the frontal sinus (FS) lead to advances in forensic dentistry.

Aim: To evaluate the dimensions and patterns of FS as observed on posterior-anterior (PA) cephalogram for personal and gender identification.

Materials and Methods: A total of 700 PA Cephlograms, 350 males and 350 females were selected. The mean dimensions and patterns of the FS in males and females were determined and evaluated.

Results: On intergroup comparison, the difference in dimensions of males and females were statistically significant with p-value of 0.000 . The present study revealed that out of 700, FS symmetry and asymmetry was observed in 386 (55.14\%) and 165 $(23.57 \%)$ individuals respectively. The FS aplasia was seen in $149(21.2 \%)$ individuals.

Conclusion: The morphometric analysis of FS can serve as an adjunct to other methods of personal and gender identification.
\end{abstract}

Keywords: Personal identification, Frontal Sinus, PA cephalogram.

\section{Introduction}

Frontal Sinus, Sella turcica, Nasal Septum, vascular groove patterns etc., are unique human anatomical structures for personal and gender identification in forensics on the fully developed skeleton. ${ }^{1}$ The growth and development of FS manacle the manifestation of sexually dimorphic features and is unique even in monozygotic twins. ${ }^{2}$ The dead and deceased human remains identification forms cardinal element in medico-legal cases. ${ }^{3}$

Personal identification includes establishing the identity of an individual. In forensics, human skull radiographs can be compared for personal identification in living, decayed or deceased individuals or in cases of mass calamities (such as earth quakes, tsunamis, landslides, bomb blasts). ${ }^{4}$

Investigations, in which ante mortem and postmortem radiographic records are compared, are commonly used for personnel identification both in human remains and in living individuals. For forensic identification of unknown decomposed or deceased individuals, the singulatity of anatomical structures and their variations plays a significant role. ${ }^{5}$

Therefore, the present study was conducted to assess FS dimensions and patterns as observed on posterioanterior (PA) cephalogram, for personal and gender identification.

\section{Materials and Methods}

PA cephalograms of 700 individuals visiting the Department of Oral Medicine and Radiology, College of Dental Sciences, Davangere city, between the age group of 18-45 years were enrolled in the study. Ethical clearance was taken from the institutional committee before commencing the study. Individuals with developmental defects or pathologies, craniofacial syndromes, endocrinal or metabolic disorder or with history of craniofacial trauma or surgery were not included in the present study. The PA cephalograms were assessed for the morphometric evaluation of FS.

Measurements were done using ROMEXIS software. The width of the FS was calculated as the maximum lateral limits from central septum and height was measured from frontonasal suture to the superior most point of the FS. (Fig. 1). ${ }^{6}$

Anatomically, FS was classified as symmetrical, asymmetrical (right or left dominant), unilateral or bilateral aplasia. The difference between right and left side dimensions of FS was divided by their greatest dimension and was multiplied by 100 . FS was considered as symmetrical, in case the obtained percentage is less than 20, and if it is more than 20, FS was classified as asymmetrical (Fig. 2).

The results were analyzed using Statistical Package of Social Sciences (SPSS) software version 21. The dimensions of FS between males and females were compared using paired t-test. The $\mathrm{p}$-value less than 0.05 was considered as significant. 


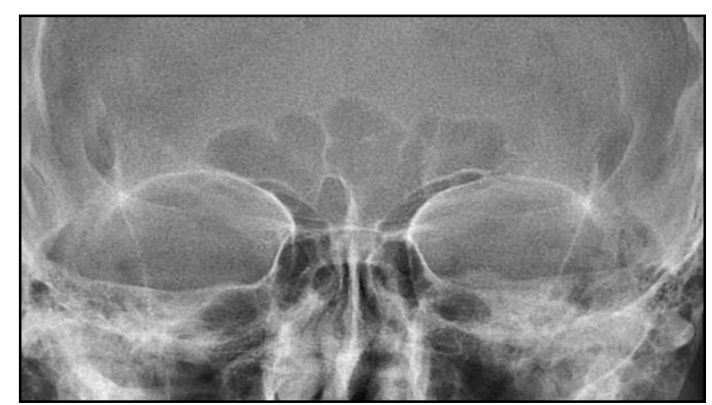

Fig. 1: Dimensions for measuring height and width of FS

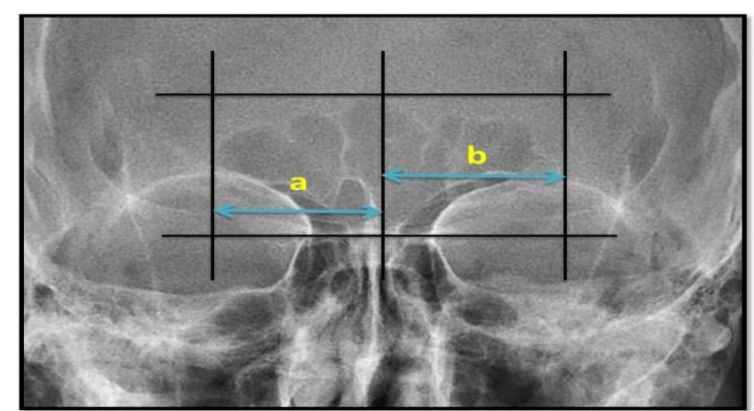

Fig. 2: Method for determining symmetrical or asymmetrical frontal sinus pattern

\section{Results}

The mean age of males and females enrolled in the study was $31.42 \pm 5.62$ years and $25.86 \pm 6.93$ years respectively. The mean width of FS with SD in males and females was $57.83 \pm 5.59 \mathrm{~mm}$ and $36.27 \pm 6.62$ $\mathrm{mm}$ respectively while the mean height with SD in males and females was $24.76 \pm 3.48 \mathrm{~mm}$ and $18.83 \pm$ $2.82 \mathrm{~mm}$ Therefore, the differences of males and females dimensions were statistically significant in both the genders with p-value of 0.000. (Table 1 and Graph 1)

Out of 700, FS symmetry, left dominant asymmetry and right dominant asymmetry was observed in $386(55.14 \%), 119(15.57 \%)$ and $56(8.0 \%)$ individuals respectively. Out of 149 (21.28\%) individuals with aplasia, unilateral aplasia was seen in 86 (left- 52 and right-34) while bilateral aplasia was observed in 63 individuals.

Table 1: Dimensions of Frontal Sinus among males and females

$P$ value less than 0.05 was considered as significant

\begin{tabular}{|l|c|c|c|}
\hline & Males (mm) & Females $(\mathbf{m m})$ & p Valve \\
\hline Width & $57.83 \pm 5.59$ & $36.27 \pm 6.62$ & $0.000^{*}$ \\
\hline Height & $24.76 \pm 3.48$ & $18.83 \pm 2.82$ & $0.000^{*}$ \\
\hline
\end{tabular}

Table 2: Distribution of frontal sinus patterns

\begin{tabular}{|l|c|c|c|}
\hline Classification & \multicolumn{2}{|c|}{ Number of individuals } & Total (percentage) \\
\hline & Males & Females & \\
\hline Symmetry & 206 & 180 & $386(55.14 \%)$ \\
\hline Left Dominant Asymmetry & 74 & 45 & $119(15.57 \%)$ \\
\hline Right Dominant Asymmetry & 22 & 34 & $56(8.0 \%)$ \\
\hline Left Unilateral Aplasia & 36 & 16 & $52(7.42 \%)$ \\
\hline Right Unilateral Aplasia & 16 & 18 & $34(4.85 \%)$ \\
\hline Bilateral aplasia & 38 & 25 & $63(9.0 \%)$ \\
\hline
\end{tabular}

Graph 1: Dimensions of frontal sinus among males and females

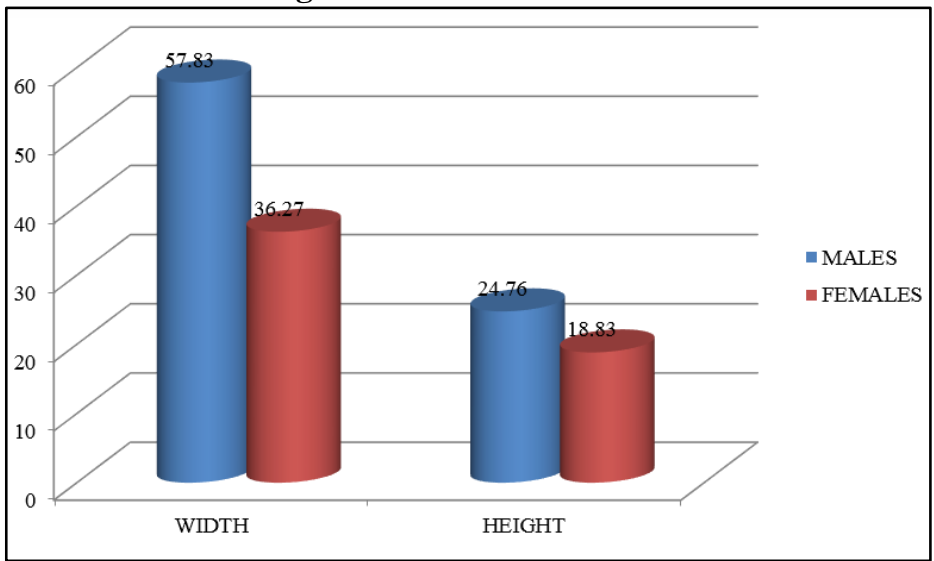


Graph 2: Distribution of frontal sinus patterns

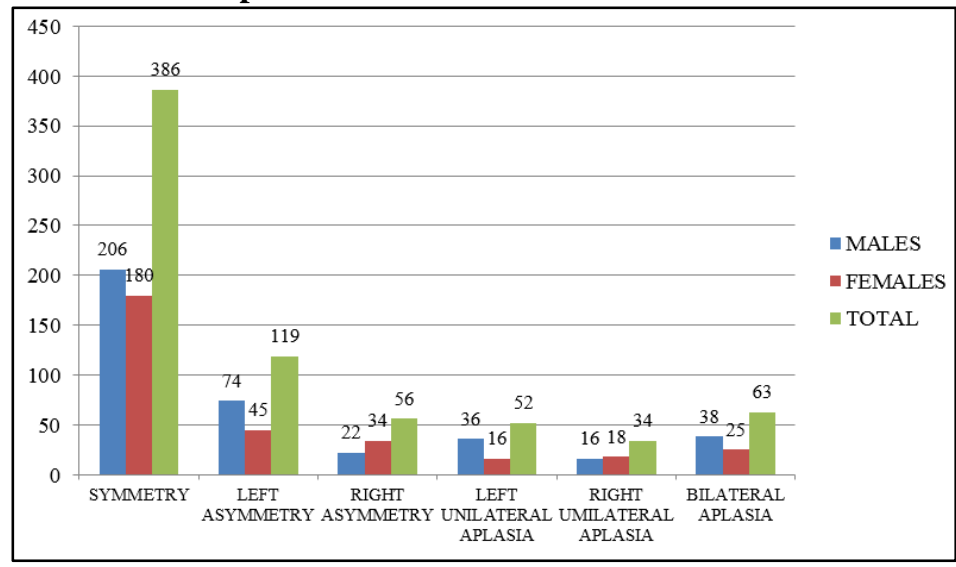

\section{Discussion}

Frontal sinus analysis has proven to be a very useful tool for identification purposes in forensic dentistry. ${ }^{7}$ The singularity of FS is due to its asymmetrical morphology which was first stated by Zukerkandl (1875). ${ }^{8}$ The present study was intended to measure dimensions of FS and to analyze its pattern using a single radiograph with minimal distortion and maximal details.

The individuals above the age of 18 were taken into consideration due to variations in size and shape of FS during growth and development of individual which can be influenced by genetic, hormonal or environmental elements which is in accordance with studies conducted by Libersa and Faber (1957), Krogman (1962), and Porbonikova (1974). ${ }^{9}$ In the present study, individuals till the age of 45 were enrolled as with the advancing age, variations such as bone resorption are the common findings. ${ }^{10}$

In the present study, equal number of males and females were taken into consideration which is in compliance with the studies published in 2007 (Camrgo $\mathrm{RJ}$ et al), 2010 (Maria PD et al), 2013 (Mathur $\mathrm{H}$ et al), 2014 (Hamed SS et al), 2016 (Tiwari P et al), 2017 (Verma K et al). ${ }^{1,9,11-14}$ While in some studies published in 2015 (Verma P et al) and 2017 (Nagaraj T) includes unequal distribution of males and females. ${ }^{6}, 15$ Similarly, another study published in 2010 includes 116 males and 29 females. ${ }^{16}$

The mean width of FS in males and females was $57.83 \pm 5.59 \mathrm{~mm}$ and $36.27 \pm 6.62 \mathrm{~mm}$ respectively while the mean height with SD in males and females was $24.76 \pm 3.48 \mathrm{~mm}$ and $18.83 \pm 2.82 \mathrm{~mm}$ Therefore, the differences of males and females dimensions were statistically significant in both the genders with p-value of 0.000 . The above data suggested that mean width and height of FS is greater in males as compared to females and can be used as a criterion for gender determination in forensics which was in accordance with the studies published by Yoshino M (1987) ${ }^{17}$ and Verma K et al (2017). ${ }^{1}$
The present study is in accordance with the studies conducted by Nagaraj T et al $(78 \% \text { and } 11.4 \%)^{15}$ and Verma $\mathrm{K}$ et al $(77.5 \% \text { and } 22.5 \%)^{1}$ stating that FS symmetry and asymmetry were found to be $55.14 \%$ and $23.57 \%$, respectively. Unilateral absence of FS was seen in $86(12.2 \%)$ of 700 individuals. These findings are in accordance with the studies done by Verma $\mathrm{K}$ et al (2017) $)^{1}$ and Tiwari $P$ et al $(2016)^{14}$ with $8.7 \%$ and $13.75 \%$ cases respectively and in contrast to the studies done by David M P et al (2010), ${ }^{9}$ Gopal et al $(2017)^{18}$ and Nagaraj T (2017) $)^{15}$ who observed $6 \%, 2.5 \%$ and $5.7 \%$ respectively.

In the present study, Bilateral aplasia was found to be $63(9.0 \%)$ in our study which was in total contrast with the studies done by Gopal et al. $(2017)^{18}$ who did not observe in any case, David M P et al $(2010)^{9}$ with $4 \%$, Tiwari $P$ et al $(2016)^{14}$ with $5 \%$ and Nagaraj $\mathrm{T}$ et al $(2017)^{15}$ with $4.6 \%$ cases and in favor of Taniguchi et al $(2003)^{19}$ in which $10.8 \%$ cases were found.

The present study was conducted using only one radiograph which adequately demonstrates FS morphology with minimal distortion and maximum detail. Similar studies published in literature which involving morphometric analysis using one radiograph were conducted by Reddy S et al (2014), ${ }^{20}$ Mohan V et al (2015), ${ }^{21}$ Nagaraj T et al (2017) $)^{15}$ and Verma K et al (2017). ${ }^{1}$ However, in contrast, Camargo RJ et al (2007), ${ }^{11}$ Rubira-Bullen IRF et al (2010) ${ }^{16}$ and Patil N et al $(2012)^{5}$ used Caldwell view in their studies.

Limitations of the study involves smaller sample size along with the age limits i.e. individuals in the age range of 18 to 45 were included in the study. Secondly, a better precise tool i.e. Cone beam computed tomography (CBCT) will reduces the chances of error. Therefore, larger sample size with age wise distribution with an advanced radiographic technique is recommended.

\section{Conclusion}

The morphometric analysis of frontal sinus involving its dimensions and patterns using a single radiograph with maximal details can be used as 
an adjuvant for personal and gender identification in forensic dentistry.

\section{References}

1. Verma K, Nahar P, Singh MP, Mathur H, Bhuvaneshwari S. Use of Frontal Sinus and Nasal Septum Pattern as an Aid in Personal Identification and Determination of Gender: A Radiographic Study. Journal of clinical and diagnostic research: JCDR. 2017;11(1):ZC71.

2. Tang JP, Hu DY, Jiang FH, Yu XJ. Assessing forensic applications of the frontal sinus in a Chinese Han population. Forensic Sci Int. 2009;183:104.e1-3.

3. Kanchan T, Krishan K. Personal Identification in Forensic Examinations. Anthropol. 2013;2:114.

4. Modi JP (2011) A Textbook of Medical Jurisprudence and Toxicology, 24th Edn, LexisNexis Butterworths, Nodia.

5. Patil N, Karjodkar FR, Sontakke S, Sansare K, Salvi R. Uniqueness of radiographic patterns of the frontal sinus for personal identification. Imaging science in dentistry. 2012;42(4):213-7.

6. Verma P, Verma KG, Khosa R, Kumar S, Basavaraju S, Patwardhan N. Combined use of frontal sinus and nasal septum patterns as an aid in forensics: A digital radiographic study. North American journal of medical sciences. 2015;7(2):47.

7. Campobasso CP, Dell'Erba AS, Belviso M, Di Vella G. Craniofacial identification by comparison of antemortem and postmortem radiographs: two case reports dealing with burnt bodies. The American journal of forensic medicine and pathology. 2007;28(2):182-6.

8. Zukerkandl E, Lichtwitz L, Garnault P. Anatomy of the frontal sinus. In normal and pathological anatomy of the nasal cavity. Vol 1, 3rd ed. Paris: G Masson; 1895. p. 349-61

9. David MP, Saxena R. Use of frontal sinus and nasal septum patterns as an aid in personal identification: A digital radiographic pilot study. Journal of forensic dental sciences. 2010;2(2):77.

10. Quatrehomme G, Fronty P, Sapanet M, Grévin G, Bailet $\mathrm{P}$, Ollier A. Identification by frontal sinus pattern in forensic anthropology. Forensic Sci Int. 1996;83:147-53.

11. Camargo RJ, Daruge E, Prado FB, Caria PHF, Alves MC, Silva RFet al. The frontal sinus morphology in radiographs of Brazilian subjects: its forensic importance. Braz J Morpholo Sci. 2007;24(4):239-243.
12. Mathur H, Mathur A, Ahmed J, Khorate M and Tripathi P. Conventional frontal sinus imaging in identification of sex: Original study in population of Udaipur city, India. $J$ Med Sci Clin Res. 2013;1(1):33-37.

13. Hamed SS, Badrawy AM and Fattah SA Gender identification from frontal sinus using multi-detector computed tomography. J Forensic Radiol Img. 2014;2(3):117-120.

14. Tiwari P, Bhovi TV, Jaju PP, Gupta M, Shrivastava K. Frontal Sinus-A Useful Personal Identification Tool. Journal of Oral Medicine, Oral Surgery, Oral Pathology and Oral Radiology. 2016;2(1):11-22.

15. Nagaraj T, Nigam H, Santosh HN, Sumana CK, Gogula $\mathrm{S}$, Sahu P. Personal identification using frontal sinus and nasal septum patterns in forensic medicine: A retrospective digital radiographic study.

16. Rubira-Bullen IRF, Rubira CMF, Sarmento VA and Azevedo RA. Frontal sinus on facial plain radiographs. $J$ Morphol Sci. 2010;27(2):77-81.

17. Yoshino M, Miyasaka S, Sato H, Seta S. Classification system of frontal sinus pattern by radiography. Its application to identification of unknown skeletal remains. Forensic Sci Int. 1987;34(4):289-99.

18. Gopal KS, Vijayan BP. Significance of frontal sinus and nasal septum patterns in personal identification in forensics: A retrospective CBCT study. Int J Oral Health Med Res. 2016;2:57-62.

19. Taniguchi M, Sakoda S, Kano T, Zhu BL, Kamikodai Y, Fujita MQ, et al. Possible use of nasal septum and frontal sinus patterns to radiographic identification of unknown human remains. Osaka City Med J. 2003;49(1):31-38.

20. Reddy S, Alapati S and Kotha P. Unleash the unknownFrontal sinus and nasal septal patterns in personal identification. 2014;2(6):141-145.

21. Mohan V, Kumar JS, Kumar SC and Neha. Morphometric evaluation of frontal sinus in relation to gender- A forensic study. University J Dent Sci. 2015;1(2):7-11. 